\title{
Aeromagnetic evidence for the arcuate shape of Mahanadi Delta, India
}

\author{
Goutam Kumar Nayak, Ch. Rama Rao, and H. V. Rambabu \\ National Geophysical Research Institute, Hyderabad-500007, India
}

(Received September 22, 2005; Revised April 7, 2006; Accepted April 11, 2006; Online published September 16, 2006)

\begin{abstract}
The stream network comprising Mahanadi and its tributaries, viz. Katjhori, Devi, Koyakhai, Kushbhadra and Bhargavi, cut transversely the ESE-WNW trending basement structure in the Cuttack-Paradip-Puri section and diverge radially from one another near and around Cuttack. The Mahanadi river flows in an ESE-WNW direction, the Katjhori and Devi rivers flow in a NW-SE direction and Koyakhai, Kushbhadra and Bhargavi River in an almost N-S direction. The general southeasterly direction of these rivers and the delta formation was thought to be continued throughout the Quaternary period and the delta was a case of superposition upon the deformational structures derived from the erosional surfaces covered by recent sediments.

Analysis of the aeromagnetic anomaly field of the Mahanadi Delta area of the on-shore portion has indicated three prominent structural trends in ESE-WNW, NW-SE and N-S directions along which the rivers Mahanadi/Chitratala, Katjhori and Devi, Koyakhai, Kushbhadra and Bhargavi flow, respectively. The tectonic disturbance along the N-S direction, in the western part of Bhubaneswar-Puri section, seems to have been controlling the Koyakhai and Kushbhadra and Bhargavi river system, following the possible trace of $85^{\circ} \mathrm{E}$ Ridge, whereas the concealed NW-SE trending Mahanadi graben trend is inferred to be the probable cause for the NW-SE flow of the Katjhori river in the middle portion south of Cuttack and the ESE-WNW flow of the Mahanadi and Chitratala rivers in the Cuttack-Paradip section controlled by the Eastern Ghat trend.
\end{abstract}

Key words: Delta, Eastern Ghat trend, aeromagnetic anomaly field, Mahanadi graben.

\section{Introduction}

The digitate Ganga delta, the arcuate Mahanadi and Godavari deltas, the lobate shaped Krishna delta, the cuspate form of the Swarnarekha delta, and the triangular shaped Cauvery delta of the Indian peninsula lie on the east coast of India. Generally, the shapes of the deltas are said to be dependent on many factors which include the geology and structure, river discharge and load, grain size, flood frequency, climate, vegetation, wave energy, water temperature, and so on (Morgan, 1970). The arcuate Mahanadi delta is the third largest with a drainage spread of about $1,32,000$ sq. $\mathrm{km}$. along the east coast and is conspicuous with radially divergent drainage comprising the Mahanadi/Chitratala, Katjohri/Devi and Koyakhai/Daya/Kushbhadra/Bhargavi rivers (Fig. 1). Mahanadi originates from the hills of the Bastar district of Madhya Pradesh and reaches the Bay of Bengal after traveling a distance of about $800 \mathrm{~km}$. During its sojourn, the river flows over varied geological terrains and discharges huge quantities of sediment in the pericratonic on- and off-shore Mahanadi basins.

An attempt has been made in this paper to study one of the important factors of delta formation, viz., the structure in the Mahanadi delta area, bounded by lats. $18^{\circ} 51^{\prime} \mathrm{N}$ and $21^{\circ} 49^{\prime} \mathrm{N}$ and Longs. $85^{\circ} 00^{\prime} \mathrm{E}$ and $87^{\circ} 25^{\prime} \mathrm{E}$. The structural fabric of the basement is masked by a thick cover of recent alluvium in this delta area. So qualitative and quantitative

Copyright (c) The Society of Geomagnetism and Earth, Planetary and Space Sciences (SGEPSS); The Seismological Society of Japan; The Volcanological Society of Japan; The Geodetic Society of Japan; The Japanese Society for Planetary Sciences; TERRAPUB analysis of aeromagnetic data has been made, in conjunction with available borehole and Deep Seismic Sounding (DSS) data, to delineate structural trends which might throw light on the influence of the structure for the radially divergent pattern of the Mahanadi and its tributaries.

\section{Geology and Structure of the Mahanadi Delta}

The Mahanadi basin is one of the five sedimentary basins situated along the east coast of the Indian peninsula formed as a result of rifting and break-up of Gondwana land during the Jurassic period. The Mahanadi's on- and off-shore basins trend along the Eastern Ghats, which are usually aligned along the NE-SW to ENE-WSW direction. These basins have formed along the ancient lineaments/shears belonging to the Archaean age, which have controlled the subsidence and faulting. Vast tracts of granite, khondalite, charnockite, and anorthosite are exposed towards the west of the Mahanadi delta (Fig. 2). These rocks belong to the Eastern Ghat group and are disposed in the form of hillocks striking NE-SW and/or ENE-WSW directions.

In the northeastern part of the on-shore basin, the iron ore formations of the Eastern Ghats are exposed. The Upper Gondwana beds, known as Atagarh sandstone, are exposed in the northern part of the delta between Cuttack and Bhubaneswar. The onshore basin is fully covered by recent alluvium brought down by the Mahanadi and its tributaries (Fig. 2).

Fuloria (1993), synthesizing borehole and other geophysical data, envisages three major structural provinces, viz. Mesozoic (mainly Cretaceous), Paleocene, and MioceneRecent. The basement of the Mahanadi delta is of the conti- 


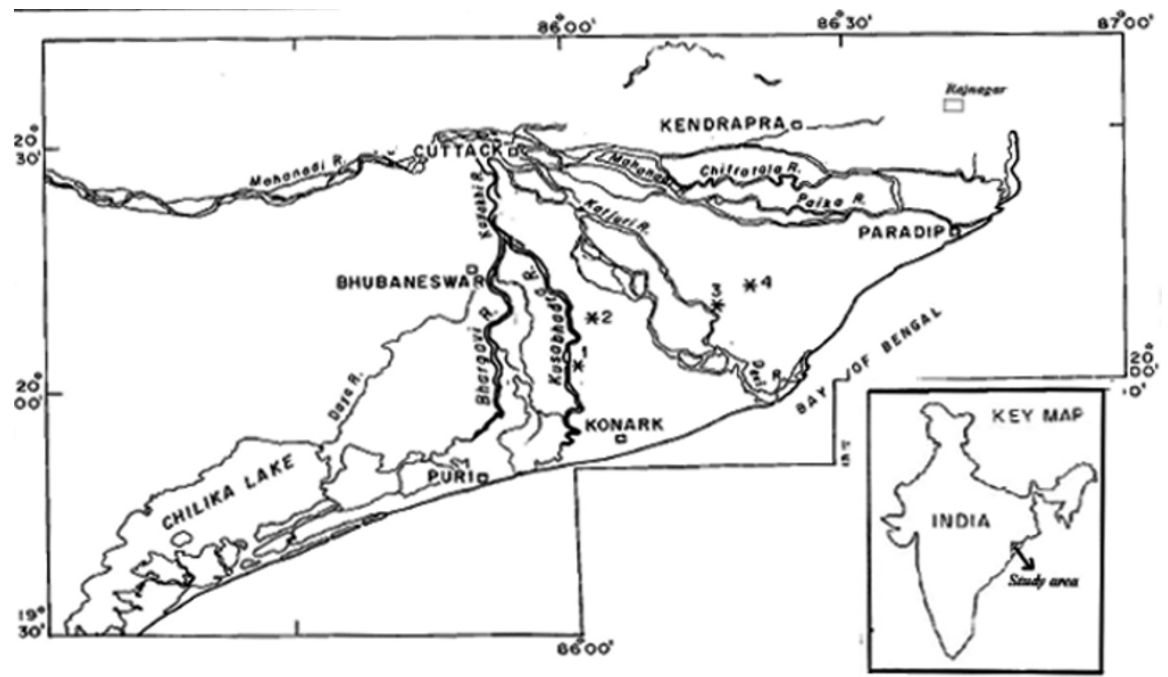

Fig. 1. Mahanadi and its tributaries observed from the radially diverging drainage patterns in the region of Cuttack. Inset shows the location of the Mahanadi Delta. *1 Nimapara, *2 Niali, *3 Balikuda, *4 Ersama.

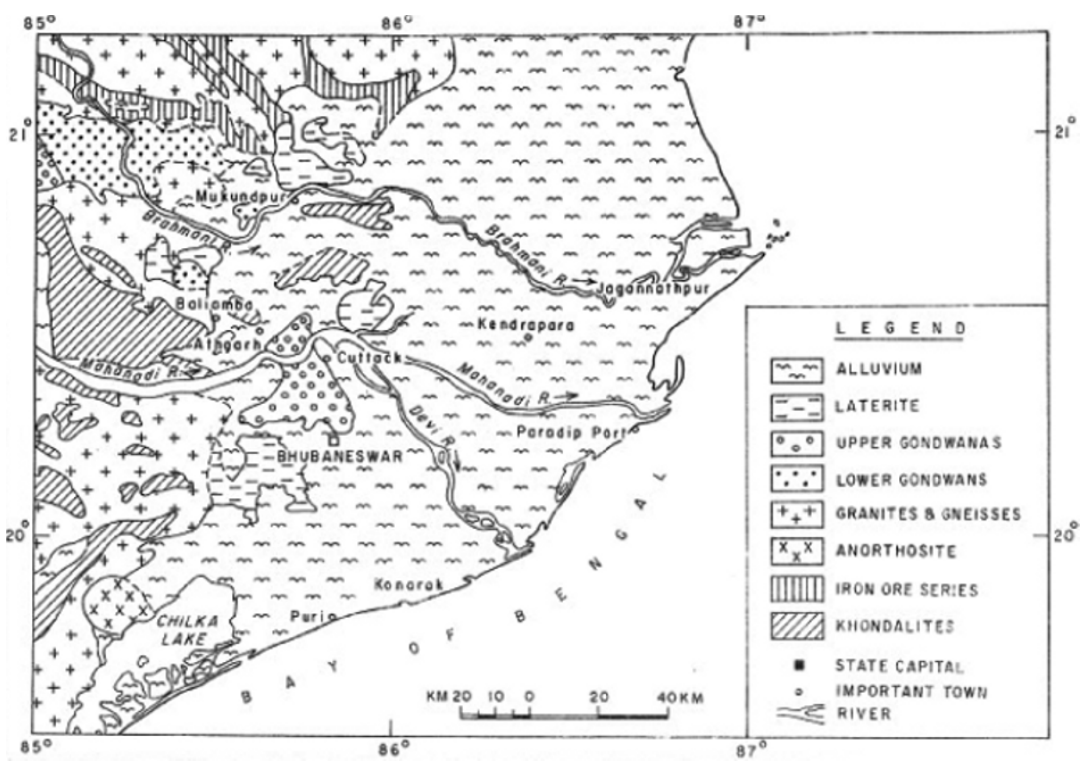

Fig. 2. Geological map of the Mahanadi delta and its surroundings.

nental type and is composed of granites and gneisses of the Pre-Cambrian age. He opines that the on-shore Mahanadi basin is significantly different from the off-shore part.

Early Cretaceous volcanics are found in the off-shore wells, whereas they are absent in some of the wells in the on-shore area. Late Cretaceous sediments are present in the off-shore basin, whereas they are totally absent in the on-shore basin. Rocks of Paleocene and Eocene ages are absent in the central part of the on-shore basin (delta), whereas they are present in the off-shore part. No Oligocene sedimentation is reported from both basins. Miocene, $\mathrm{Pa}-$ leocene, and Pleistocene-Recent sediments are present in both on- and off-shore basins.

The basement here is traversed by a number of major faults having ENE-WSW, NNE-SSW and NNW-SSE trends. Lateral movements along the strike slip sinistral faults in the NNW-SSE direction have divided the region into transverse blocks. Genetically the transverse faults trending in the NNW-SSE direction are older than the ENEWSW longitudinal faults (Fuloria, 1993).

\section{Drainage Network of Mahanadi Delta}

The superimposed drainage network with radially divergent rivers of the arcuate Mahanadi delta has a length of $\sim 300 \mathrm{~km}$ and extends from the western end of Chilaka lake in the west to Rajnagar in the northeast. The Mahanadi delta is of the progradational type with various drainage patterns. The delta-building activity seems to have been initiated after a major regression of the EarlyMiddle Miocene and continued till Recent with northward progression (Bharali et al., 1991). Huge amounts of sediments derived from the intensely eroded rugged terrain under hot and humid monsoonal climate are deposited in the Mahanadi basin (Enayat Ahmed, 1985). Niyogi (1975), based on photo geomorphic mapping, geological history, and palaeogeologic development of coastal plain, feels that 


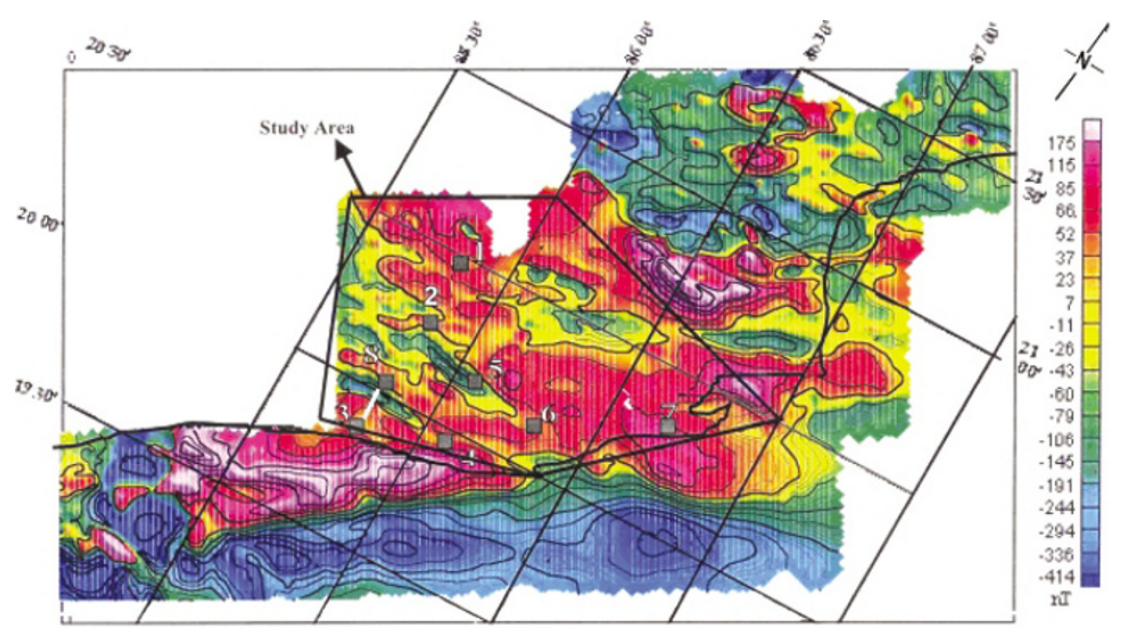

Fig. 3. Total intensity aeromagnetic image/contour map of the Mahanadi and adjoining areas. Survey carried out by NGRI for OIL. The contour intervals are 10, 50, 100, and 1000 (Thick one) nT (1 Cuttack; 2 Bhubaneswar, 3 Puri, 4 Konark, 5 Niali, 6 Balikuda, 7 Paradip, 8 Delang) (Inclination I = 30 Declination $\mathrm{D}=0.4^{\circ}$ ).

the delta-building process continued throughout the Quaternary period. Sambasiva Rao et al. (1978) have identified strand lines, $\sim 10$ meander belts, and some morphostructures and lineaments/fractures. Deltaic sedimentation started at the close of the Early-Middle Miocene on the paleogeographic terrains and sediment thickness is observed to be vary widely.

The stream network comprising the Mahandi and its tributaries, viz. Katjohri, Devi, Koyakhai, Kushbhadra, Daya, and Bhargavi (i) cut transversely the ENE-WSW trendinginferred basement structures which are derived from gravity and aeromagnetic data in the Cuttack-Paradip-Puri section, (ii) diverge radially from one another near and around Cuttack, (iii) the Mahanadi/Chitratala rivers flow along an ESE-WNW direction, (iv) the Katjohri and Devi in a NWSE direction and (v) the Koyakhai, Kushbhadra and Bhargavi channels in almost an N-S direction (Fig. 1).

\section{Aeromagnetic Data}

The National Geophysical Research Institute (NGRI) has collected aeromagnetic data for Oil India Ltd. (OIL) in the on- and off-shore regions of Mahanadi basin. About 32,000 sq. $\mathrm{km}$ areas have been covered at a flight line spacing of $2 \mathrm{~km}$ at an altitude of $600 \mathrm{~m}$ a.m.s.l. The flight lines are oriented in the $\mathrm{N} 30^{\circ} \mathrm{W}$ direction and flown at a constant height above the terrain. Most of the study area is monotonously plain and the flight height remained almost constant in the delta area. The main objective of this survey was to obtain an overview of the basement configuration (Babu Rao et al., 1982) and to deduce the thickness of overlying sediments. Figure 3 is the total intensity aeromagnetic contour map of the area. Aeromagnetic map provides useful information in deducing major and minor structures and/or tectonic features under sediment cover and differentiate zones of lithological variations within the crustal rocks. A set of characteristic features, found in any magnetic contour map, like elongations, nosings, flexures, tight and diffused bandings in the contours, are generally associated with the fault/lineaments. Alignment and persistence of magnetic anomaly closures (either positive or negative) along lines with relief on both sides in any contour map generally associated with faults (Gay, 1972). Dislocations, shifts and drag features of the contours and the trends are associated with the strike slip environment. A careful analysis of the magnetic map of the alluvium-covered Mahanadi delta of the present study area has been made to derive the magnetic lineaments. The magnetic lineaments are inferred by following the criteria given by Gay (1972), on the 1:250,000 scale of the total intensity contour map of the study area. The structural trends and lineaments were also inferred from the filter maps on the same scale and then combined together (1:250,000 scale) to produce the complete structural map of the study area. The inferred lineament map is superimposed on a drainage system map of the same scale and this combined map is then reduced in size and presented in Fig. 4.

(i) Analysis of aeromagnetic data: Based on the above criteria as enunciated by Gay (1972), qualitative interpretation has been made on the total intensity aeromagnetic data of the study area. Figure 4 shows the inferred magnetic lineaments superposed on the drainage network of the Mahanadi delta. It is evident from the figure that there are three prominent sets of magnetic lineaments, one set trending along an ENE-WSW direction (F1, F2, LA1, LA8 and LA4), the second set of lineaments along a NW-SE direction (LN3 and LN4) and the third set of lineaments LN1, $\mathrm{LN} 2$ in a N-S direction.

The EW to ESE-trending Mahanadi, Chitratala and Paika rivers seem to be controlled by the first set of lineaments. The northern lineament, F1, is associated with the Cuttack depression and the southern lineament, LA8, seems to be controlling and forming the northern and southern boundaries, respectively, for this river system. The ENE to NE trending lineaments, F2 and LA7, cutting across the rivers might be acting as parallel faults with a gradational downthrow of the basement towards the SE.

Quantitative analysis of the magnetic anomalies taken from this area indicate a generalize slope towards the SE with a magnetic basement depth varying from $290 \mathrm{~m}$ near Cuttack, $350 \mathrm{~m}$ between F2 and LA7, $850 \mathrm{~m}$ between LA7 and LA6 and $2050 \mathrm{~m}$ after LA6, whose depth is associated 


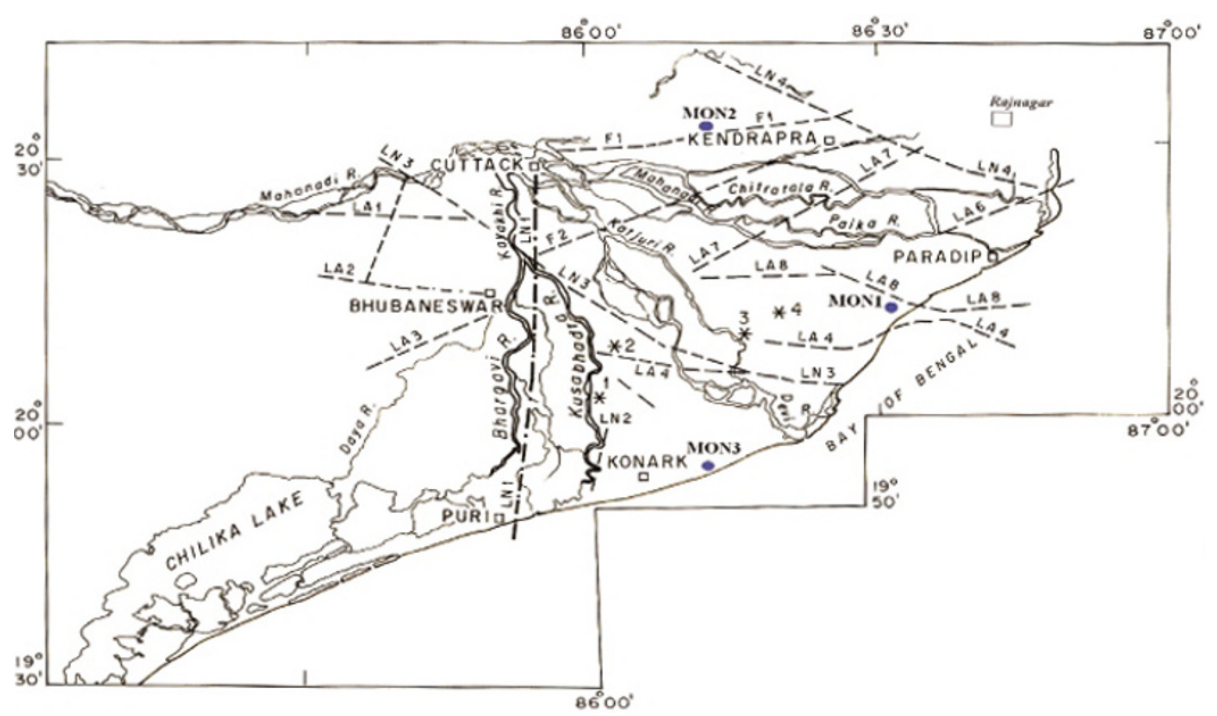

Fig. 4. The inferred magnetic lineaments superposed on the Mahanadi drainage system. (i) The lineaments viz. F1, F2, LA1, LA8 and LA4 are trending ENE-WSW and ESE- WNW. (ii) The lineaments LN3 and LN4 are trending NW-SE. (iii) The set of lineament LN1, LN2 are trending along N-S direction. (iv) Blue color solid circles MON1, MON2 and MON 3 are represent the Deep borewell dug by OIL.

with the depth of the basement in the Paradip depression.

The Devi and Koyakhui rivers seem to be flowing along the NW-SE direction following the trend of the lineament pattern LA3 and LA4 associated with the Mahanadi Graben trend (Atchuta Rao et al., 1999).

The N-S trend of the Bhargavi and Kusabhadra, in our opinion, appears to be controlled by the lineaments LN1 and LN2. The subtle expression of the lineament LN1 is inferred from the dislocations along a N-S direction observed in the magnetic closure pattern which might indicate a strike-slip environment possibly associated with the extension of $85^{\circ}$ E Ridge. Ramana et al. (1997), Subrahmanyam et al. (1999) and Subrahmanyam et al. (1994, 1997) have studied the offshore gravity, magnetic and seismic data, and inferred the possibility of the extension of $85^{\circ} \mathrm{E}$ Ridge under the Mahanadi basin. Nayak and Rama Rao (2004) have interpreted the intense offshore magnetic anomalies and their dislocations, south of Chilka Lake, as due to the existence of $85^{\circ} \mathrm{E}$ Ridge.

(ii) Quantities analysis:

(a) Methodology: 41 aeromagnetic anomalies obtained from the total intensity contour map of scale 1:63360 scale, have been quantitatively analyzed using the MAGMOD software of Paterson, Grant and Wattson Ltd., Canada (1986). This software is designed to derive, from observed magnetic anomalies, the shape and size parameters such as depth, width, dip, magnetization, position, thickness, base slope, and base level for 2D, 2.5D and 3D models; in the present case we consider that the sources causing the anomalies in the study area are of $2.5 \mathrm{D}$ body. Observed anomaly data is provided along with the initial estimates for depth and other parameters. The initial constraints are determined in the present study from the wavelength of the anomalies, straight/maximum slope of the anomalies, and from available drilling data so as to reduce, as far as possible, non-uniqueness, in interpretation.
The software uses the Marquardt (1963) algorithm, and provides a best-fit to the observed anomaly after a reasonable numbers of iterations.

As the study area is filled with nonmagnetic sedimentary rocks overlying the crystalline basement, so the average values of magnetization ranging between 1.194 and $2.387 \mathrm{~A} / \mathrm{m}$ units are assigned for the anomalies obtained in the study area. All the depths obtained using MAGMOD software, from a 1:63360 scale anomaly map, are then projected onto a map of 1:250000 scale and the depth contour map is prepared for the study area. This depth contour map is compared with the basement depth map of the study area obtained from the DSS and drill data of OIL and DANIDA project.

(b) Analysis: the central Mahanadi delta bounded by Bhubaneswar, Ersama, Niali and Balikuda (Fig. 5) is covered with recent sediments ranging in thickness from 80 to $1000 \mathrm{~m}$. Borehole data (unpublished DANIDA Proj., Mahalik, 2000) from some of the localities in this part also confirm the range of thickness derived from analysis of magnetic anomalies.

This part of the basement of the delta region is bounded in the south by

(i) the Puri - Konark depression, with a maximum sediment thickness of $2500 \mathrm{~m}$.

(ii) the Paradip depression in north-east with an estimated thickness of $\sim 1400 \mathrm{~m}$.

(iii) Cuttack depression in north with $3000 \mathrm{~m}$ thick Gondwana sediments resting directly on the basement.

OIL had drilled three deep boreholes in the on-shore Mahanadi delta area (Fig. 5). The borehole data from the well (MON3) near Konark gives a depth of $2500 \mathrm{~m}$ to the basement, which corroborates well with the inference from the magnetic data. The DSS data also indicates the depth 


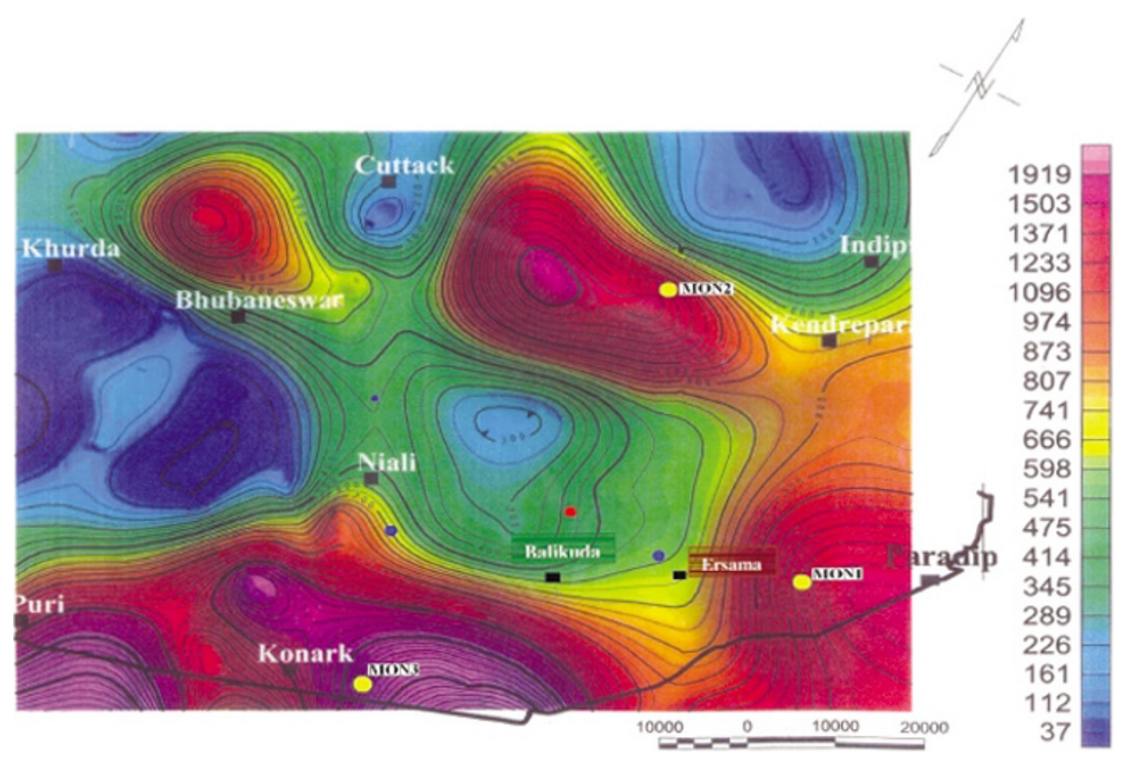

Fig. 5. Image/contour map showing the depth to the magnetic basement derived from the analysis of 41 magnetic anomalies. (1) The large circle filled with yellow color with nomenclature MON1, MON2 and MON3, is the drilled well location of OIL. (2) Small circles filled with red and blue colors indicate the well drilled for groundwater exploration by the DANIDA Project. The red color filled circle indicates the well touching the crystalline basement at a depth of $473 \mathrm{~m}$. The blue color filled circles are not touching the basement and their depths vary from 150 to $300 \mathrm{~m}$.

to the basement as 2500 m near Konark (Kaila et al., 1987) and thus confirms the magnetic interpretation.

Similarly, the DSS data (Kaila et al., 1987) and borehole data near the well (MON1) (Fuloria, 1991) at Paradip also shows a depth to the basement of $\sim 1400 \mathrm{~m}$, which corroborates well with the magnetic anomaly interpretation. However, the depth $1300 \mathrm{~m}$ derived from magnetic interpretation to the magnetic basement near Cuttack is underestimated. The actual depth to the basement inferred from the DSS and borehole data is $3000 \mathrm{~m}$. The discrepancy at this locality is perhaps caused due to the cumulative effects of the presence of volcanic layers at an average depth of $1300 \mathrm{~m}$ within the Gondwana sediments.

(iii) Other Geophysical evidence:

(a) Borehole data: The borehole data provided by Mahalik et al. (2000) along the Puri - Delang section adjacent to the inferred magnetic lineament LN1, indicates a steep gradient from Delang in the north to Puri in the south. The river Bhargavi flows along this gradient in a N-S direction and thus the river system appears to be controlled by the $\mathrm{N}-\mathrm{S}$ trending magnetic lineament LN1.

(b) DSS data: Kaila et al. (1987) have observed a peculiar behavior of first arrivals and heavy attenuation at the near-distance leading to large jumps in travel times in the region south of Cuttack, indicating the phenomenon of shingling. This disturbance might have been associated with a triple junction as pointed out by Burke and Dewy (1973) from where the formation of delta and radial divergence of the river system took place.

\section{Conclusions}

Analysis of aeromagnetic data of the central part of the Mahanadi delta, in the East Coast of India has indicated: (i) A shallow basement with a sediment thickness ranging from 80 to $600 \mathrm{~m}$. The central shallow basement is surrounded by different depressions and is radially dipping.

(ii) This radial dip of the basement and the existence of heterogeneity near and around Cuttack must have controlled the sedimentation process and later the formation of an arcuate delta with a diverging tributary system.

(iii) The N-S trending lineament is inferred to be associated with the extension of the $85^{\circ} \mathrm{E}$ ridge below the delta along which Kusubhadra and Bhargavi Rivers flow.

Acknowledgments. The authors thank Dr. V. P. Dimri, Director, NGRI for his permission to publish this paper. Thanks are due to the reviewers who have critically reviewed the manuscript to improve the quality and also to Mrs. K. Venkata Lakshmi for her assistance. The authors appreciate the neat drawings of Shri B. Vyaghreshwarudu.

\section{References}

Atchuta Rao, D., Ch. Rama Rao, and D. S. Bhaskara Rao, Extension of the Intracratonic Mahanadi rift towards the east coast of India-An inference from aeromagnetic and gravity, J. Geol. Soc. India, 53, 7177, 1999.

Babu Rao, V., D. Atchuta Rao, P. V. Sankar Narayana, and C. Ratnam, Aeromagnetic survey over a part of Mahanadi basin and adjoining offshore region, Orissa, India, Geophys. Res. Bull., 40, 219-226, 1982.

Bharali, B., S. Rath, and R. Sarma, A brief review of Mahanadi delta and the deltaic sediments in Mahanadi basin, Mem. Geol. Soc. Ind., 22, 3149, 1991.

Burke, K. and J. F. Dewy, Plume generated triple junctions: Key indicators in applying plate tectonics to old rocks, J. Geol., 8, 406-433, 1973.

DANIDA, Orissa drinking water supply project, Hydrogeological Investigation, DANIDA, Ministry of Foreign Affairs., Vol. 1, 1993.

Das, S., Ground water resource and its management in Mahanadi delta, in Mahanadi Delta Geology, Resources \& Biodiversity, edited by N. K. Mahalik, Sri Guru Gouranga Press. IRC village, Bhubanesware-15, pp. 95-117, 2000.

Enayat Ahmed, Geomorphology, Kalyani Publishers, India 1985. 
Fuloria, R. C., Geology and Hydrocarbon prospect of Mahanadi basin, India. Proc. 2nd Seminar on "Petroliferous Basin in India", Indian Petroleum, edited by S. K. Biswas, et al., Publication Dehra Dun, 3, 355-369, 1993.

Gay, S. P., Fundamental characteristics of aeromagnetic lineaments: Their geological significance and their significance to geology, Tech. Publication No. 1, American Stereo company, Salt Lake City, Utah, 1972.

Kaila, K. L., H. C. Tewari, and D. M. Mall, Crustal structure and delineation of Gondwana basin in Mahanadi delta area, India, from Deep Seismic Soundings, J. Geol. Soc. India, 29, 293-308, 1987.

Mahalik, N. K., Mahanadi Delta, Geology, Resources \& Biodiversity, Sri Guru Gouranga Press, IRC village, Bhubanesware-15, 95-117, 2000.

Marquardt, D. W., An algorithm for least-square optimization of non linear parameter, J. Soc. Indust. Appl. Math., 11, 344-361, 1963.

Morgan, J. P., Depositional processes and product in the deltaic environment, in Deltaic Sediment, edited by J. P. Morgan, Modern and Ancient. Soc. Econ. Paleontologists and Mineralogists Spl. Publ. 15, 3147, 1970.

Nayak, G. K. and Ch. Rama Rao, Structural configuration of Mahanadi offshore basin, India: An Aeromagnetic Study, Marine Geophysical Researches, 23, 471-479, 2002.

Niyogi, D., Quaternary Geology of the coastal plain of West Bengal and Orissa, Indian J. Earth Science, 2(1), 51-61, 1975.

Paterson, Grant and Watson, Program documentation-MAGMOD version1.4, Magnetic interpretation software Library, Paterson, Grant and Watson Ltd. Toronto, Canada, 1986.
Radhakrishna, I., Saline and Fresh water interface structure in Mahanadi delta region, Orissa, India, Environmental Geology, 40(3), 369-380, 2000.

Ramana, M. V., V. Subrahmanyam, A. K. Chaubey, T. Ramprasad, and K. V. L. N. S. Sarma, Structure and origin of the 850 E Ridge, J. Geophys. Res., 102, 17995-18012, 1997.

Sambasiva Rao, M., K. Nageswara Rao, and R. Vaidyanadhan, Morphology and evolution of Mahanadi and Brahmani-Baitarani deltas, Proc. Symp. Morphology and Evolution of Landform, Dept. of Applied Geology, Delhi University, Delhi-7, 241-248, 1978.

Subrahmanyam, A. S., K. S. R. Murthy, T. C. S. Rao, M. Malleswara Rao, A. S. Lakshminarayan, and K. Venkateswarlu, A two-stage evolution of Visakhapatnam-Paradip shelf, East Coast of India, from magnetic study, Proceedings of Indian Academy of Science (Earth Planet. Sci.), 103, 17-26, 1994.

Subrahmanyam, A. S., K. S. R. Murthy., Rao, S. Lakshminarayan., M. M. Malleswara Rao, K. Venkateswarlu, and T. C. S. Rao, Magnetic expression of some major lineaments and Cretaceous quite zone in the Bay of Bengal, Geo-Marine Letters, 17, 202-206, 1997.

Subrahmanyam, C., N. K. Thakur, T. Gangadhar Rao, Ramesh Khanna, M. V. Ramana, and V. Subrahmanyam, Tectonics of the Bay of Bengal: new insights from Satellite-Gravity and Ship-Borne geophysical data, Earth and Planetary Science Letters, 171, 237-251, 1999.

G. K. Nayak (e-mail: goutam_mi@hotmail.com), Ch. Rama Rao, and H. V. Rambabu 